\title{
KAWASAN KOTA RAMAH BAGI PEJALAN KAKI Studi Kasus Ubud, Gianyar, Bali
}

\author{
Ferdinand ${ }^{1}$, R Trisno ${ }^{2}$, S Gunanata ${ }^{3}$ \\ 1 Program Studi Desain Interior Universitas Tarumanagara Jakarta, Indonesia \\ 2,3 Program Studi Arsitektur Universitas Tarumanagara, Jakarta, Indonesia \\ *E-mail: ferdinand.kendall1@gmail.com
}

\begin{abstract}
Abstrak - Kemajuan jaman telah mengubah banyak hal dalam kehidupan kita sehari-hari. Pada masa lalu, kota-kota merupakan sebuah lingkungan yang nyaman bagi pejalan kaki. Namun pada masa sekarang ini, dengan kemajuan teknologi manusia lebih cenderung bergantung pada mobil dan kendaraan bermotor lainnya dalam menggunakan ruang kota. Banyak elemen-elemen ruang kota yang sudah tidak diperuntukan lagi sesuai dengan fungsinya, salah satunya adalah trotoar jalan yang difungsikan untuk pejalan kaki. Maka dari itu penelitian ini ditulis dengan tujuan untuk mengidentifikasi elemen-elemen pendukung kawasan walkable guna menciptakan kawasan kota yang ramah bagi pejalan kaki dari berbagai golongan. Penelitian ini dilakukan dengan cara membandingkan dan menganalisis antara objek penelitian yang berupa studi kasus dengan rencana dan strategi perencanaan kota walkable yang dikeluarkan oleh Australia Barat, Walk WA: A Walking Strategy for Western Australia 2007-2020 dengan maksud untuk menghasilkan rekomendasi yang dapat digunakan oleh pemerintah untuk mengevaluasi serta meningkatkan infrastruktur termasuk sarana dan prasarana pendukung kawasan yang ramah pejalan kaki. Studi kasus yang dipilih pada penelitian ini adalah kawasan kota Ubud yang terletak di Gianyar, Bali dengan pembatasan wilayah Jalan Raya Ubud yang terletak tepat di pusat Ubud. Dari hasil penelitian ini dapat disimpulkan bahwa Jalan Raya Ubud memiliki potensi untuk menjadi sebuah kawasan walkable yang ramah bagi pejalan kaki dengan catatan perlu peningkatan dalam perencanaan sarana dan prasarana pendukung terciptanya kawasan ramah pejalan kaki seperti akses, estetika, keamanan dan keselamatan serta kenyamanan.
\end{abstract}

Keywords: Kota, Walkable, Kawasan

\section{I. PENDAHULUAN}

Dengan semakin majunya peradaban yang ditandai dengan semakin majunya ilmu pengetahuan dan teknologi, dewasa ini manusia semakin berusaha mengurangi ketergantungannya kepada kondisi lingkungan alamnya untuk memperoleh kenyamanan bermukim, justru sebaliknya mereka mereka-reka keadaan lingkungannya untuk memperoleh kenyamanan tersebut. Yaitu melalui peningkatan kualitas lingkungan agar memenuhi kebutuhan rohani dan jasmaninya. Menurut Jan Gehl, kegiatan di luar ruang (outdoor activities) dalam suatu permukiman dapat dibagi menjadi tiga kegiatan, yaitu: necessary activities, optional activities, dan social activities [1]. Kegiatan berjalan kaki misalnya, akan dilakukan oleh seseorang tanpa menghiraukan kualitas lingkungan bila hal itu merupakan necessary activities, namun seseorang akan mempertimbangkan kualitas lingkungan bila kegiatan tersebut merupakan optional activities. Sedangkan social activities merupakan hasil dari keduanya. Dengan demikian semakin tinggi kualitas suatu lingkungan mendorong semakin tinggi pula frekuensi terjadinya kegiatan-kegiatan tersebut.

Disadari atau tidak, pengaruh kualitas lingkungan terhadap terjadinya outdoor activities secara umum mendasari penciptaan area pejalan kaki (untuk selanjutnya istilah pejalan kaki akan disebut juga sebagai pedestrian) di perkotaan. Kota-kota pada masa lalu pada umumnya berkarakter sebagai lingkungan yang nyaman bagi para pejalan 
kaki. Namun dengan semakin maraknya kehadiran mobil yang semakin banyak dan beraneka ragam, karakter lingkungan kota berubah bukan lagi diperuntukkan bagi pejalan kaki, tetapi untuk lalu lintas kendaraan beroda. Kehadiran mobil menyebabkan terjadinya persaingan yang tidak seimbang dengan pejalan kaki untuk menggunakan ruang kota yang semakin langka.

Kondisi lingkungan pejalan kaki secara cepat menurun kualitasnya. Kawasan pusat kota menderita masalah penurunan kualitas yang paling berat dibanding kawasan lain di kota. Daya tariknya menurun dan berangsur-angsur berubah menjadi lingkungan yang tidak nyaman dan mulai ditinggalkan oleh para pejalan kaki, dan fungsinya mulai terganggu. Bila suatu pusat kota terganggu fungsinya sebagai pusat kegiatan dan pelayanan kota, maka terancam pula citranya sebagai tempat yang nyaman untuk bertempat tinggal dan bekerja yang berarti kampanye yang tidak baik bagi kegiatan produktivitas dan perekonomian kota. Perubahan karakter lingkungan bagi pejalan kaki di pusat kota ini telah menyulut ide untuk memperbaiki dan meningkatkan kualitas lingkungan tersebut dan mendorong upaya membentuk area-area baru bagi pejalan kaki yang tanggap terhadap berbagai pengaruh lingkungan sekaligus untuk memenuhi kebutuhan tersedianya lingkungan pejalan kaki yang nyaman, sehingga membentuk karakter kota menjadi lebih manusiawi, maka dari itu peneliti ingin mengangkat judul dengan tema kawasan kota ramah pejalan kaki dengan melakukan analisa menggunakan Walk WA: A Walking Strategy for Western Australia 2007-2020 pada kota Ubud, Gianyar, Bali sebagai salah satu kawasan kota tujuan wisata di pulau Bali.

\section{MATERIAL DAN METODE}

\subsection{Studi Kasus}

Dalam penulisan ini, peneliti mengambil studi kasus kota Ubud, Gianyar, Bali. Ubud merupakan sebuah wilayah dipinggiran Kota Gianyar, Bali dengan luas $42,38 \mathrm{~km}^{2}$, namun mengalami perkembangan yang sangat pesat dibandingkan dengan daerah lainnya. Hal ini dikarenakan Ubud memiliki potensi dan daya tarik yang lebih dibandingkan dengan wilayah lain di sekitarnya.

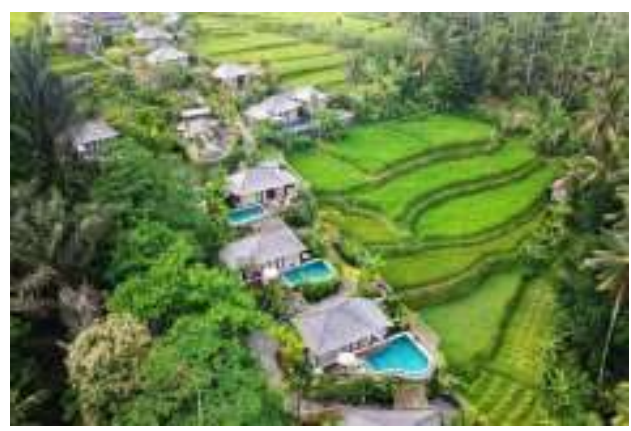

Gambar 1. Gambar salah satu bagian di kawasan Ubud, Gianyar, Bali Sumber:

https://www.idntimes.com/travel/destination/cameliasafitri/6-destinasi-wisata-kece-di-ubud-c1c2

Ubud yang dulunya dikenal sebagai daerah pedesaan dengan hamparan sawah dan pemandangan alamnya kini menjadi pusat pertumbuhan ekonomi perdagangan dan jasa. 
Fakultas Seni Rupa dan Desain - Universitas Tarumangara

Ferdinand, R Trisno, S Gunanata ; Halaman 1 - 7

Struktur masyarakat Desa Ubud dalam perkembangannya diorganisir dalam bentuk kerajaan, dengan raja pertama Tjokorda Gede Putu Kandel, kemudian diubah menjadi kepunggawaan, keperbekelan, dan kini menjadi Kelurahan Ubud.

Kehidupan di kawasan ini dikenal sangat kaya akan khasanah budaya, daya tarik tersebut membuat beberapa seniman menetap di kawasan ini dan mulai menularkan pengaruh seninya kepada masyarakat setempat sehingga mulailah Ubud dikenal dengan karya dan kebesaran tokoh-tokoh seninya. Kehadiran wisatawan di satu sisi memberi pengaruh peningkatan ekonomi masyarakat Ubud tapi di sisi lain juga menimbulkan perubahan tatanan dalam masyarakat Ubud.

Wilayah yang dijadikan objek penelitian pada penulisan paper ini adalah hanya sepanjang ruas jalan utama, Jalan Raya Ubud yang terletak di pusat kota Ubud dan sebagai daya tarik utama wisatawan dengan adanya pertokoan dan café-café sepanjang ruas jalan ini.

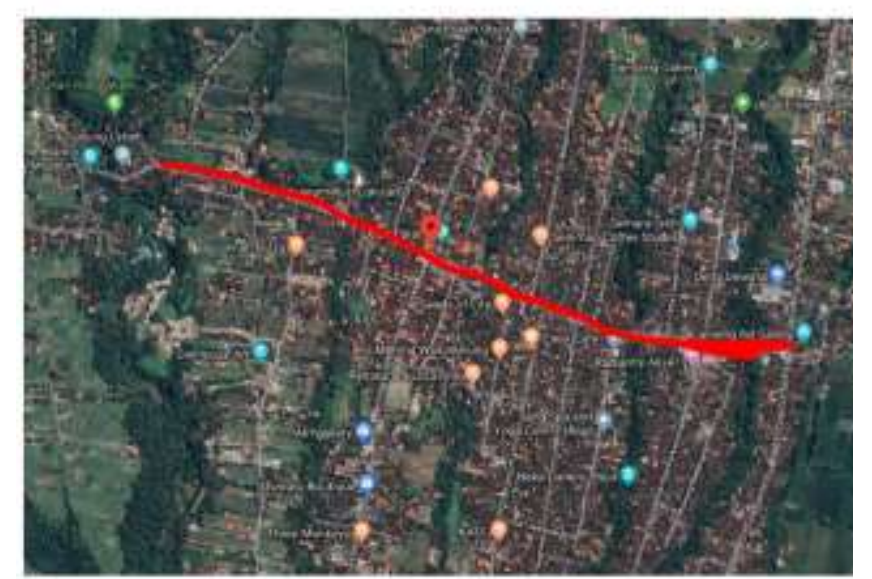

\subsection{Material}

Walkability menurut Land Transport New Zealand pada pedestrian planning and design guide, adalah suatu kondisi yang menggambarkan sejauh mana suatu lingkungan dapat bersifat ramah terhadap para pejalan kaki [2]. Walkability dapat diartikan sebagai suatu ukuran tingkat keramahan suatu lingkungan terhadap para pejalan kaki dalam suatu area. Arti yang tertanam dalam frasa "walkable city" adalah berbagai makna dan implikasi dari beragam budaya yang dapat digunakan untuk kehidupan sehari-hari[3]. The vision of the Walk WA: A Walking Strategy for Western Australia (2007 -2020) mengatakan bahwa untuk dapat mendukung terciptanya suatu lingkungan yang walkable, terdapat empat hal yang harus di perhatikan, yaitu [4]:

\section{a. Akses;}

Menciptakan suatu akses yang mudah menuju ruang terbuka dengan cara berjalan kaki, bagi semua orang. Serta memastikan tersedianya fasilitas yang dapat menunjang bagi kaum manula, difabel serta orang-orang yang membawa kereta bayi dengan menciptakan jalur yang lebar dan landai serta di tandai dengan ada nya signage. Selain itu perlu juga diperhatikan tempat parkir bagi kendaraan bermotor dan non bermotor serta lokasi pemberhentian bus.

\section{b. Estetika;}

Gambar 2. Jalan utama yang dijadikan objek penelitian, yaitu Jalan Raya Ubud Sumber: Diolah dari google maps, 2018 Perlunya menciptakan suatu lingkungan yang memberikan pengalaman menyenangkan dalam 
lokasi, dengan memberikan perhatian terhadap penataan landscape, serta pengendalian terhadap pengelolaan sampah.

\section{c. Keselamatan dan Keamanan;}

Para pejalan kaki harus dapat merasa bahwa mereka dan barang-barang mereka aman dari tindak kejahatan. Para pejalan kaki harus dapat menikmati perjalanan merekda dengan bersantai, hal ini dapat di bentuk dengan menciptakan suatu lingkungan yang terpelihara dengan mengadopsi prinsip desain yang dapat mencegah terjadinya tindak kejahatan.

\section{d. Kenyamanan.}

Para pejalan kaki harus dapat merasanya nyaman ketika berjalan pada suatu lingkungan, hal ini dapat diciptakan dengan menyediakan fasilitas seperti adanya bangku-bangku umum, shelter tempat beristirahat serta adanya fasilitas air minum bagi publik.

Selain itu untuk menciptakan lingkungan yang walkable perlu adanya perhatian terhadap faktorfaktor seperti integrasi antar komunitas dengan perumahan, pertokoan, tempat bekerja, fasilitas sekolah, taman serta akses menuju kendaraan umum yang saling terkoneksi dengan jalur pejalan kaki yang di sertai orientasi yang tepat.

Berdasarkan pemaparan teori singkat diatas, maka penulis menjabarkan parameter-parameter yang digunakan untuk meninjau lebih lanjut menyangkut hal-hal yang perlu di analisa dalam mewujudkan kota yang ramah terhadap pejalan kaki pada wilayah kota Ubud, Gianyar, Bali. Adapun parameter-parameter tersebut adalah sebagai berikut:

Tabel 1. Parameter yang digunakan untuk meninjau kota ramah pejalan kaki pada wilayah kota Ubud, Gianyar, Bali

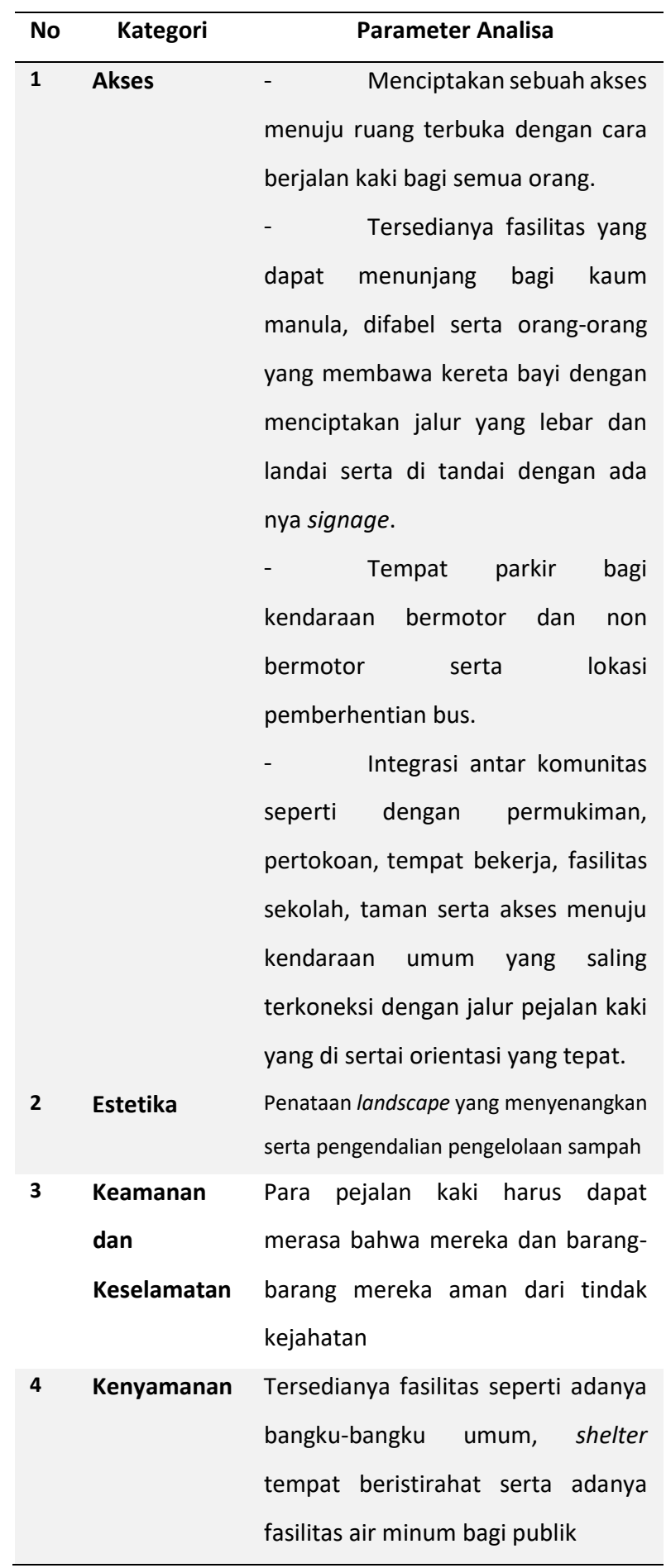

Sumber: Hasil pengolahan pribadi, 2018 
Fakultas Seni Rupa dan Desain - Universitas Tarumangara

Ferdinand, R Trisno, S Gunanata ; Halaman 1 - 7

\section{HASIL DAN PEMBAHASAN}

1. Akses

Akses jalan pada jalan Raya Ubud berbentuk linear tidak berliku-liku. Secara umum, Jalan Raya Ubud dapat dilewati dengan cara menggunakan kendaraan bermotor (mobil, motor, bus) atau dengan berjalan kaki. Luas jalan utama yang tidak terlalu lebar menjadikan Jalan Raya Ubud sering mengalami kemacetan, ditambah masih banyaknya kantong-kantong parkir motor di sisi jalan karena tidak tersedianya area khusus untuk parkir, maka dari itu banyak dari wisatawan yang lebih memilih berjalan kaki, terlebih di sepanjang ruas jalan terdapat banyak pertokoan yang menjual berbagai jenis cinderamata serta banyaknya café-café di sisi kiri dan kanan jalan.
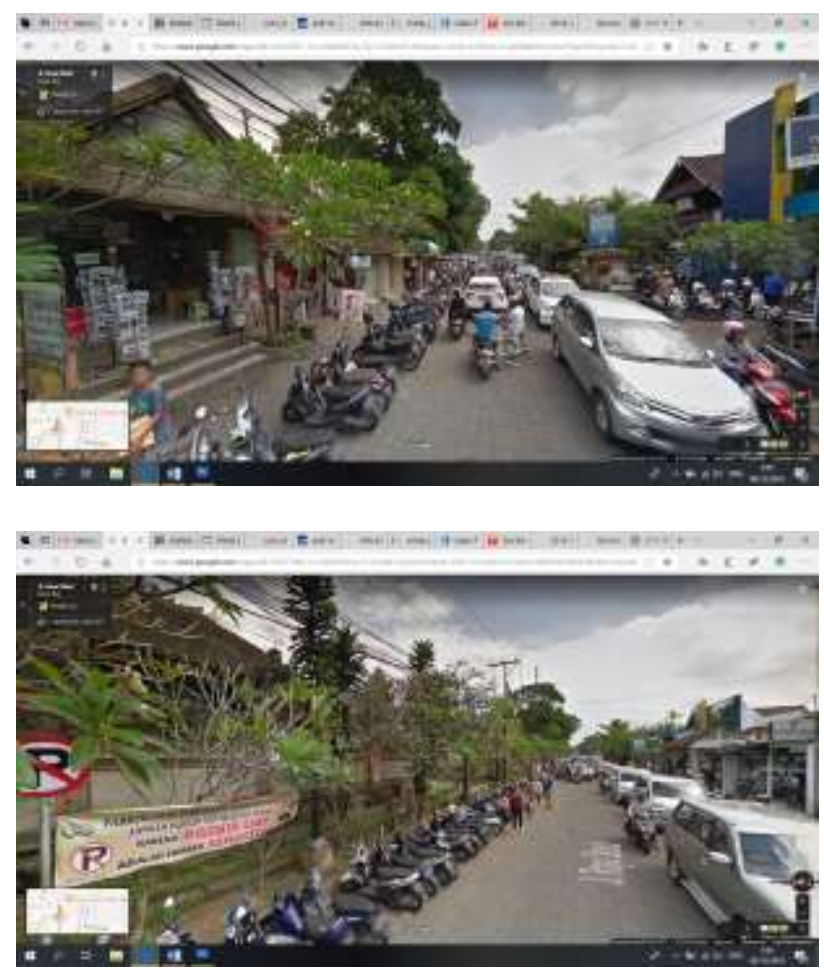

Gambar 3. Salah satu ruas Jalan Raya Ubud, dimana sisi kiri dan kanan jalan digunakan untuk parkir motor dan menimbulkan kemacetan.
Sumber: Diakses dari google street view, 2018

Selain parkir liar, masalah akses berikutnya adalah kurang memadainya fasilitas penunjang bagi kaum manula dan difabel serta bagi orang-orang yang membawa kereta bayi. Hal ini dikarenakan lebar trotoar yang sempit pada daerah-daerah tertentu namun memiliki tinggi trotoar yang tidak terlalu tinggi/landai sehingga cukup memudahkan ruang gerak kaum manula. Selain itu, paving difabel yang dipasang sepanjang ruas jalan Raya Ubud tidak dipasang secara optimal. Pada bagian-bagian tertentu, paving dipasang hanya pada satu sisi jalan.

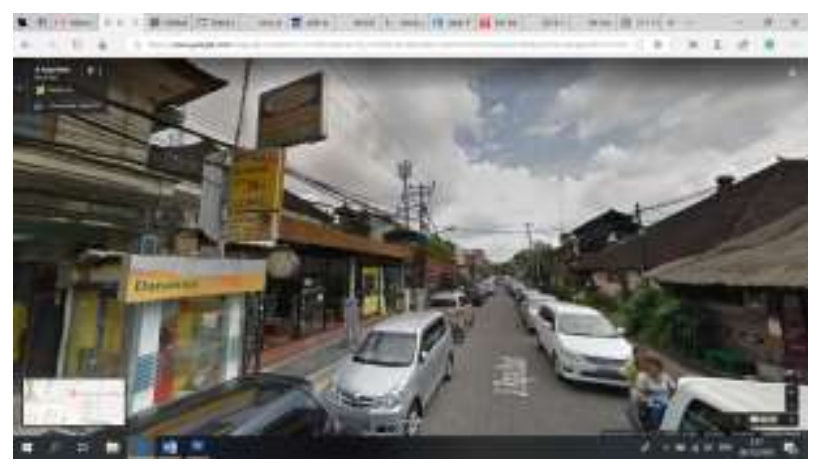

Gambar 4. Paving blok difabel yang dipasang hanya pada ruas Jalan Raya Ubud bagian sisi kanan Sumber: Diakses dari google street view, 2018

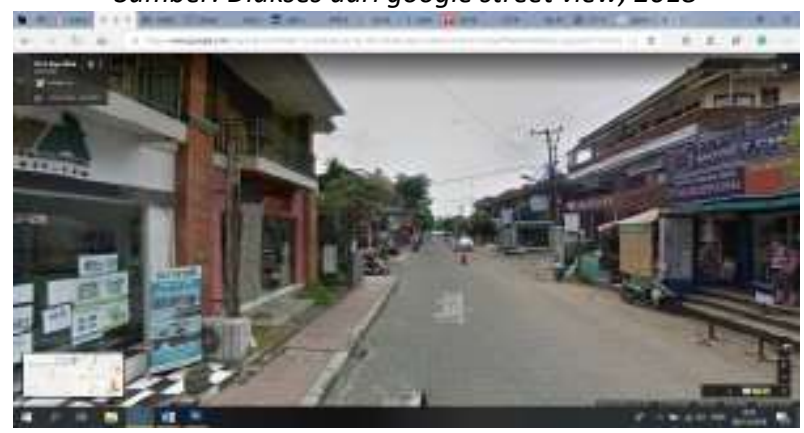

Gambar 5. Salah satu bagian pada ruas Jalan Raya Ubud yang tidak memiliki fasilitas pendukung bagi kaum difabel Sumber: Diakses dari google street view, 2018 
Selain itu, aktivitas gerak pedestrian di sepanjang Jalan Raya Ubud pada area tertentu cukup terganggu dengan adanya pedagang kaki lima yang berjualan di atas trotoar, sehingga pengguna trotoar / pejalan kaki harus turun ke jalan.

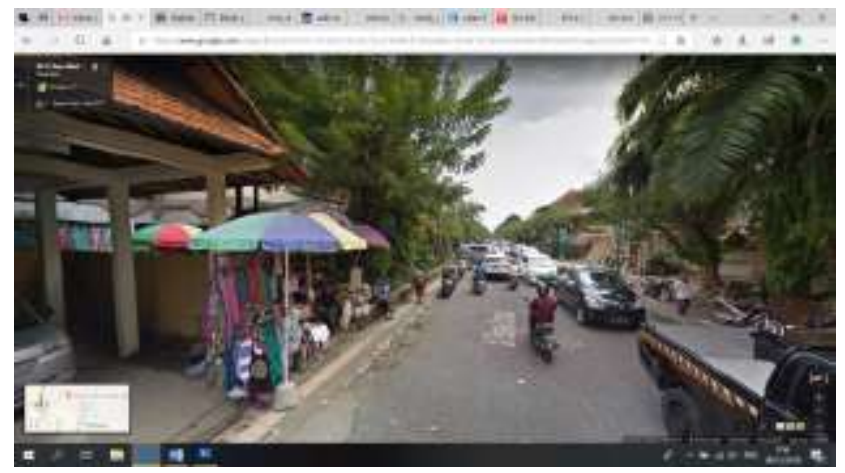

Gambar 6. Pemanfaatan trotoar oleh pedagang kaki lima yang menghambat jalur pejalan kaki

Sumber: Diakses dari google street view, 2018

Karena letaknya yang berada di pusat kota, Jalan Raya Ubud memiliki potensi untuk terjadinya integrasi mobilitas antar komunitas. Namun karena lebar jalan yang sempit, perlu ditinjau lebih jauh lagi bagaimana cara mengintegrasikan moda transportasi di wilayah Ubud. Sejauh ini, satusatunya bentuk integrasi mobilitas wisatawan adalah dengan adanya shuttle bus antara hotel dengan pusat kota Ubud.

\section{Estetika}

Estetika dalam ini adalah kelokalan kota Ubud yang terlihat secara langsung pada ruas Jalan Raya Ubud, dikarenakan pada ruas jalan ini terdapat Puri Saren yang sekarang lebih dikenal dengan Ubud Palace yang dulu merupakan pusat pemerintahan. Landscape atau dalam hal ini townscape yang tercipta pada ruas jalan ini adalah percampuran antara global dan kelokalan Bali. Dimana sepanjang jalan dihimpit oleh pertokoan-pertokoan dengan berbagai jenis brand namun di satu sisi juga, suasana Bali yang kental dapat terasa.

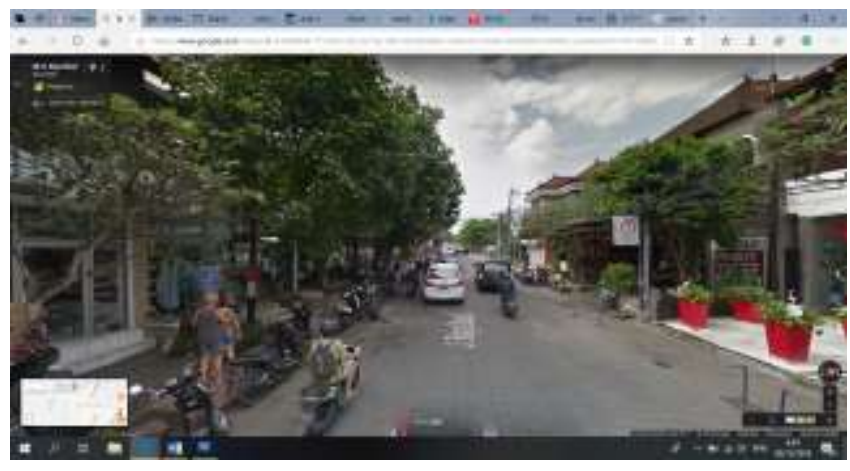

Gambar 7. Townscape pada Jalan Raya Ubud yang diisi oleh pertokoan di kiri dan kanan jalan

Sumber: Diakses dari google street view, 2018

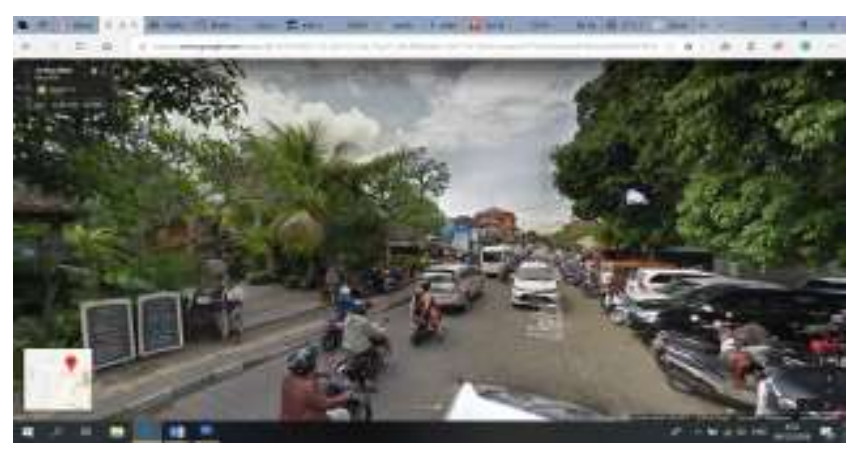

Gambar 8. Townscape pada Jalan Raya Ubud hasil pencampuran antara global dan kelokalan Bali Sumber: Diakses dari google street view, 2018

Masalah yang yang cukup terlihat dari segi estetika adalah minimnya tempat pembuangan sampah sepanjang Jalan Raya Ubud ini.

\section{Keamanan dan Keselamatan}

Keamanan sepanjang Jalan Raya Ubud terbilang cukup aman. Sedangkan dari segi keselamatan masih dapat dikatakan kurang dengan masih tidak teratur dan tertibnya trotoar dimana masih ada pedagang kaki lima yang menjajakan dagangannya di atas trotoar sehingga memaksa pengguna 
trotoar untuk turun ke jalan. Selain itu untuk keselamatan kaum difabel juga dirasa kurang apabila tanpa pengawasan dikarenakan pemasangan paving difabel yang belum optimal serta kondisi trotoar yang masih belum baik.

\section{Kenyamanan}

Untuk kenyamanan, apabila dilihat dari pemenuhan prasarana seperti street furniture masih terasa kurang. Hampir tidak ditemukan satu pun bangku jalan di sepanjang ruas Jalan Raya Ubud dikarenakan kondisi trotoar yang sempit dan tidak adanya lahan terbuka untuk taman, shelter atau sejenisnya.

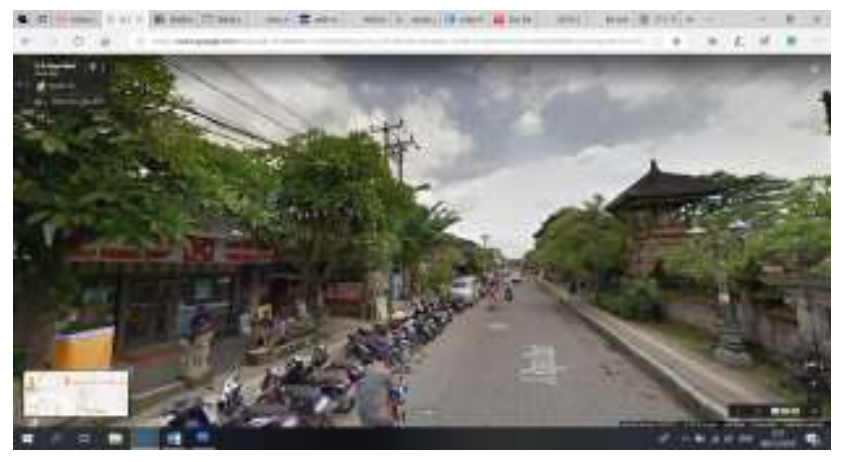

Gambar 9. Tidak ditemukannya street furniture bagi pejalan kaki untuk beristirahat sehingga para pejalan kaki tidak memiliki shelter untuk beristirahat Sumber: Diakses dari google street view, 2018

\section{SIMPULAN}

Banyak kota yang mendapat keuntungan dari kawasan walkable. Kawasan yang bersifat ramah bagi para pejalan kaki, yang dimana pejalan kaki bisa mengakses semua sarana dengan hanya berjalan kaki dan menciptakan kawasan komersial yang walkable. Upaya meningkatkan kualitas lingkungan pejalan kaki adalah strategi utama dalam mencapai hal itu sekaligus sebagai upaya dalam mempromosikan moda berjalan kaki, khususnya pada kawasan perdagangan atau perbelanjaan. Jalan Raya Ubud dalam hal ini masih belum berhasil secara sepenuhnya dalam upaya tersebut namun memiliki potensi kedepannya apabila ingin mewujudkan kawasan walkable yang ramah terhadap seluruh golongan termasuk kaum manula dan difabel.

\section{DAFTAR PUSTAKA}

Gehl, J. (1987) Life Between Building, Using Public Space, Van Nostrand Reinhold Company, New York

Abley, S, and Dr. S Turner. Predicting Walkability. Research Report Agency, Wellington: NZ Transport Research, 2011.

Demerath, Loren, and David Levinger. 2003. "The Social Qualities of Being on Foot: A Theoretical Analysis of Pedestrian Activity, Community, and Culture." City and Community 2:217-237

Premier's Physical Activity Taskforce. Walk WA: A Walking Strategy for Western Australia 2007 2020. Department of Sport and Recreation, Government of Western Australia; 2007. 